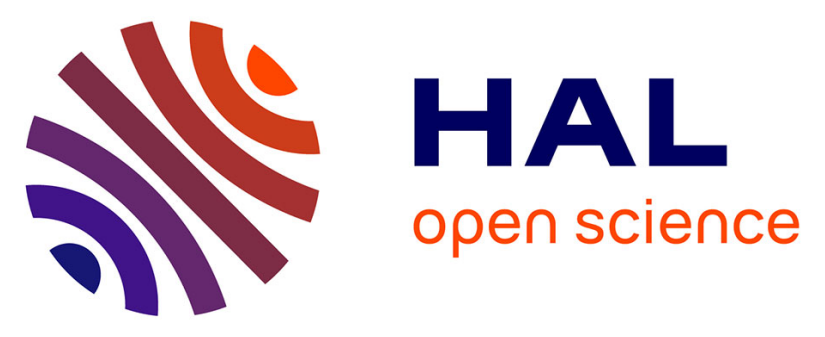

\title{
Direct Synthesis of Cycloalkanes from Diols and Secondary Alcohols or Ketones Using a Homogeneous Manganese Catalyst
}

Akash Kaithal, Lisa-Lou Gracia, Clément Camp, Elsje Alessandra Quadrelli, Walter Leitner

\section{To cite this version:}

Akash Kaithal, Lisa-Lou Gracia, Clément Camp, Elsje Alessandra Quadrelli, Walter Leitner. Direct Synthesis of Cycloalkanes from Diols and Secondary Alcohols or Ketones Using a Homogeneous Manganese Catalyst. Journal of the American Chemical Society, 2019, 141 (44), pp.17487-17492. 10.1021/jacs.9b08832 . hal-02367932

\section{HAL Id: hal-02367932 https://hal.science/hal-02367932}

Submitted on 9 Nov 2020

HAL is a multi-disciplinary open access archive for the deposit and dissemination of scientific research documents, whether they are published or not. The documents may come from teaching and research institutions in France or abroad, or from public or private research centers.
L'archive ouverte pluridisciplinaire $\mathbf{H A L}$, est destinée au dépôt et à la diffusion de documents scientifiques de niveau recherche, publiés ou non, émanant des établissements d'enseignement et de recherche français ou étrangers, des laboratoires publics ou privés. 


\title{
Direct Synthesis of Cycloalkanes from Diols and Secondary Alcohols or Ketones Using a Homogeneous Manganese Catalyst
}

\author{
Akash Kaithal, ${ }^{\dagger, \ddagger}$ Lisa-Lou Gracia, ${ }^{\ddagger}$ Clément Camp, ${ }^{\ddagger \odot}$ Elsje Alessandra Quadrelli, ${ }^{\ddagger}$ \\ and Walter Leitner*, ${ }^{*}, \S_{0}$
}

\begin{abstract}
${ }^{\dagger}$ Institut für Technische und Makromolekulare Chemie, RWTH Aachen University, Worringer Weg 2, 52074 Aachen, Germany
${ }^{\ddagger}$ Laboratory of Chemistry, Catalysis, Polymers and Processes, C2P2 UMR 5265, Université de Lyon, Institut de Chimie de Lyon, CNRS, Université Lyon 1, ESCPE Lyon, 43 Bd du 11 Novembre 1918, F-69616 Villeurbanne, France

${ }^{\S}$ Max Planck Institute for Chemical Energy Conversion, Stiftstraße 34-36, 45470 Mülheim a.d. Ruhr, Germany

Supporting Information
\end{abstract}

ABSTRACT: A method for the synthesis of substituted cycloalkanes was developed using diols and secondary alcohols or ketones via a cascade hydrogen borrowing sequence. A non-noble and air-stable manganese catalyst ( $2 \mathrm{~mol} \%$ ) was used to perform this transformation. Various substituted 1,5-pentanediols (3-4 equiv) and substituted secondary alcohols ( 1 equiv) were investigated to prepare a collection of substituted cyclohexanes in a diastereoselective fashion. Similarly, cyclopentane, cyclohexane, and cycloheptane rings were constructed from substituted 1,4-butanediol, 1,5-pentanediol, and 1,6hexanediol, and sterically hindered ketones following a $(4+1),(5+1)$, and $(6+1)$ strategy, respectively. This reaction provides an atom economic methodology to construct two $\mathrm{C}-\mathrm{C}$ bonds at a single carbon center generating high-value cycloalkanes from readily available alcohols as feedstock using an earth-abundant metal catalyst.

Crito ycloalkanes are ubiquitous structural motifs in natural products, pharmaceuticals, or materials. ${ }^{1}$ In the past, substantial efforts have been devoted to the development of synthetic strategies to build cycloalkane scaffolds. ${ }^{2}$ Among the methods to synthesize substituted cyclohexanes one can mention Diels-Alder cycloaddition $(4+2)$ followed by reduction, ${ }^{1 \mathrm{~d}, 3}$ hydrogenation of aromatic six-membered rings, ${ }^{4}$ cyclization of dihalides via Wurtz reaction, ${ }^{2 \mathrm{~b}, 5}$ dimerization of cyclopropanes, ${ }^{6}$ and Michael reaction on enolizable reagents. ${ }^{7}$ All these approaches have some drawbacks such as multistep procedures, poor regio- or stereoselectivity, narrow substrate scope, or the generation of a stoichiometric amount of chemical waste. The preparation of substituted cycloheptane rings is an even bigger challenge. At present, very few organic syntheses are known to accomplish the formation of sevenmembered rings from noncyclic common chemicals. Simple cycloheptane derivatives are typically produced via the reduction of cycloheptanone or cycloheptenes. ${ }^{8}$ Multistep procedures for the preparation of substituted cycloheptane-1,3diones, which on reduction can produce substituted cycloheptane rings, were reported from 1,2-diketones and ring expansion of cyclopentanones.' As a catalytic method, ring closing metathesis (RCM) followed by hydrogenation has generated a significant impact addressing the challenge to synthesize medium size aliphatic rings. ${ }^{10}$ Cycloisomerization followed by hydrogenation can also be considered as a possible synthetic route. ${ }^{11}$ However, these strategies require the dedicated synthesis of very specific starting materials containing the functional groups in perfect arrangement to allow for the cyclization step. Developing a straightforward, sustainable and one-step process to construct the high-value cycloalkane rings from simple building blocks is therefore an important challenge for catalysis to open new retrosynthetic pathways to these important structural units.

We report herein a broadly applicable synthetic route to cyclopentanes, cyclohexanes, and cycloheptanes from $\alpha-\omega$ diols $\left(n-\mathrm{C}_{5}, n-\mathrm{C}_{6}\right.$, and $n-\mathrm{C}_{7}$, respectively) via coupling with secondary alcohols or ketones. Alcohols and diols are ubiquitous starting materials including biomass-derived substrates making them very attractive as cheap sources for the preparation of essential and challenging building blocks. Especially $\mathrm{C}-\mathrm{C}$ bond forming reactions via hydrogenborrowing methodologies have gained significant attention recently. ${ }^{12}$ For example, metal-catalyzed $\beta$-alkylation of alcohols and $\alpha$-alkylation of ketones following this principle are well-established (Scheme 1-A). ${ }^{13}$ Recently, we reported the ruthenium and manganese catalyzed selective $\beta$-methylation of alcohols using methanol as a $\mathrm{C} 1$ source (Scheme 1-B).${ }^{14}$ Based on this experience, we speculated whether a similar approach could also be applicable for the preparation of cycloalkane rings using diols via a double alkylation methodology. Akhtar and co-workers reported the synthesis of substituted cyclohexanes using sterically hindered $1-(2,3,4,5,6$ pentamethylphenyl)ethanone and diols applying a noblemetal iridium catalyst. ${ }^{15}$ However, the reaction was exclusively restricted to the specific bulky ketone. Gratifyingly, we found that complex $\left\{\mathrm{Mn}(\mathrm{CO})_{2}(\mathrm{Br})\left[\mathrm{HN}\left(\mathrm{C}_{2} \mathrm{H}_{4} \mathrm{P}^{i} \mathrm{Pr}_{2}\right)_{2}\right]\right\}, \mathbf{1}$, known as $\mathrm{Mn}-\mathrm{MACHO}-{ }^{i} \mathrm{Pr}$, acts as a versatile catalyst for the desired reaction and makes this strategy a potentially very useful approach for the synthesis of cycloalkanes (Scheme 1-C).

Initially, using $1(2 \mathrm{~mol} \%)$ in the reaction of a stoichiometric mixture of 1-phenylethanol $2 \mathrm{a}$ and 1,5-

Received: August 26, 2019

Published: October 29, 2019 
Scheme 1. Metal-Catalyzed Coupling of Secondary and

Primary Alcohols as Motivation for the Synthetic Methodology Developed in This Work

A. Metal catalyzed $\beta$-methylation of secondary alcohols

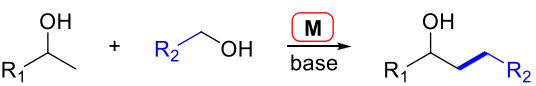

$$
\begin{aligned}
& \mathrm{R}_{1}, \mathrm{R}_{2}=\text { Aromatic, aliphatic }
\end{aligned}
$$$$
\text { M = Homogeneous metal catalyst: Ir, Ru, Mn, Fe }
$$

B. Our previous work

$$
\overbrace{\mathrm{R}=\text { Aromatic }}^{\mathrm{OH}}+\mathrm{CH}_{3} \mathrm{OH} \underset{\text { base }}{\mathrm{M}}
$$

M = Homogeneous metal catalyst: Ru, Mn

C. This work

$$
\begin{aligned}
& \text { Advantages: } \\
& \text { (i) alcohols and diols: biogenic and cheap feedstocks } \\
& \text { (ii) direct synthesis of substituted cycloalkanes } \\
& \text { (iii) earth abundant metal } \\
& \text { (iv) air stable complex }
\end{aligned}
$$

pentanediol $3 \mathrm{a}$ in the presence of $\mathrm{KO}^{t} \mathrm{Bu}$ (4 equiv) as a base gave only $16 \%$ yield of $4 a$. The low yield can be attributed to the self-condensation of the diol as a side reaction, as corroborated by the observation of the corresponding lactone

\begin{tabular}{|c|c|c|c|c|c|}
\hline & 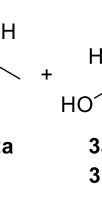 & $\begin{array}{l}\text { R } \\
\mathrm{R}=\mathrm{H}\end{array}$ & & & 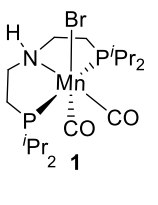 \\
\hline no. & $\begin{array}{c}\text { diol } \\
\text { (equiv) }\end{array}$ & base (equiv) & $\begin{array}{l}\text { temp } \\
\left({ }^{\circ} \mathrm{C}\right)\end{array}$ & $\begin{array}{l}\text { conv } \\
(\%)^{b}\end{array}$ & yield $4(\%)^{b}$ \\
\hline 1 & $3 \mathbf{a}(1)$ & $\mathrm{KO}^{t} \mathrm{Bu}(4)$ & 150 & 70 & 16 \\
\hline 2 & $3 a(2)$ & $\mathrm{KO}^{t} \mathrm{Bu}(4)$ & 150 & 89 & 47 \\
\hline 3 & $3 a(3)$ & $\mathrm{KO}^{t} \mathrm{Bu}(4)$ & 150 & $>99$ & 60 \\
\hline 4 & $3 \mathbf{a}(4)$ & $\mathrm{KO}^{t} \mathrm{Bu}(4)$ & 150 & 82 & 62 \\
\hline 5 & $3 a(5)$ & $\mathrm{KO}^{t} \mathrm{Bu}(4)$ & 150 & 84 & 35 \\
\hline 6 & $3 a(4)$ & $\mathrm{KO}^{t} \mathrm{Bu}(4)$ & 120 & 60 & 10 \\
\hline 7 & $3 a(4)$ & $\mathrm{KO}^{t} \mathrm{Bu}(4)$ & 170 & 98 & 74 \\
\hline $8^{c}$ & $3 a(4)$ & $\mathrm{KO}^{t} \mathrm{Bu}(4)$ & 150 & 86 & 36 \\
\hline 9 & $3 a(4)$ & $\mathrm{Cs}_{2} \mathrm{CO}_{3}(2)$ & 150 & 78 & 2 \\
\hline 10 & $3 a(4)$ & $\mathrm{NaO}^{t} \mathrm{Bu}$ & 150 & 69 & 12 \\
\hline $11^{d}$ & $3 \mathbf{a}(4)$ & $\mathrm{KO}^{t} \mathrm{Bu}(4)$ & 150 & $>99$ & 80 \\
\hline $12^{d}$ & $3 b(4)$ & $\mathrm{KO}^{t} \mathrm{Bu}(4)$ & 150 & $>99$ & 92; 90:10 d.r. \\
\hline
\end{tabular}
by GC-MS analysis. Increasing the diol-to-alcohol ratio of 2:1 improved the yield of $\mathbf{4 a}$ to $47 \%$, along with unreacted starting material and acetophenone (Table 1, entry 2). Interestingly, the Mn-catalyst 1 gave a higher yield when compared to the closely related ruthenium(II) catalyst Ru-MACHO-BH that leads to $35 \%$ of $4 \mathbf{a}$ under the same conditions. This example

Table 1. Reaction Optimization for the Synthesis of Substituted Cyclohexanes $4 a$ and $4 b^{a}$

${ }^{a}$ Reaction conditions: 1-phenylethanol $\mathbf{2 a}(0.5 \mathrm{mmol})$, diol $\mathbf{3 a}$ or $\mathbf{3 b}$, Mn-complex 1 ( $2 \mathrm{~mol} \%)$, base, and toluene $(2 \mathrm{~mL})$ were heated in a closed vessel. ${ }^{b}$ Conversion and yield were calculated using GC analysis; mesitylene was used as an internal standard. ${ }^{c} 1 \mathrm{~mol} \%$ of the Mn-complex 1 was used. ${ }^{d}$ Reaction time: $32 \mathrm{~h}$. highlights further the opportunities to use $\mathrm{Mn}(\mathrm{I})$ as a proxy for $\mathrm{Ru}(\mathrm{II})$ in pincer frameworks due to the diagonal relationship in the periodic table. ${ }^{13 c, 14,16}$ Varying the diol amount further led to a maximum of yield and selectivity of $62 \% 4 \mathrm{a}$ at $82 \%$ conversion at a 4:1 ratio (Table 1 , entries 3-5). Only minor amounts of side products stemming from aldol-type reactions of 1-phenylethanol were observed under these optimized conditions (see the SI for details).

Reducing the temperature to $120{ }^{\circ} \mathrm{C}$ gave very low conversion (Table 1 , entry 6 ). Increasing the temperature to $170{ }^{\circ} \mathrm{C}$ gave higher conversion of $98 \%$ and yield of $74 \%$ (Table 1 , entry 7) while the selectivity remained virtually constant as compared to $150{ }^{\circ} \mathrm{C}$. Decreasing the catalyst loading from 2 mol \% to $1 \mathrm{~mol} \%$ diminished the product yield and showed only $36 \%$ product formation at $86 \%$ conversion (Table 1 , entry 8). Altering the base from $\mathrm{KO}^{t} \mathrm{Bu}$ to $\mathrm{Cs}_{2} \mathrm{CO}_{3}$ and $\mathrm{NaO}^{t} \mathrm{Bu}$ also led to low product formation (Table 1 , entries 9 and 10). Finally, prolonging the reaction time from 24 to $32 \mathrm{~h}$ at $2 \mathrm{~mol}$ $\%$ catalyst loading with $\mathrm{KO}^{t} \mathrm{Bu}$ resulted in the best catalytic perfomances with $80 \%$ GC yield and $72 \%$ isolated yield after purification by column chromatography (Table 1 , entry 11). Under these optimized conditions, diol 3a could be replaced with 3-methylpentane-1,5-diol $3 \mathbf{b}$ leading to even higher yields of $4 \mathbf{b}$ ( $92 \%$ yield by GC and $81 \%$ isolated yield, Table 1, entry 12). The trans-products with both sterically demanding groups in the equatorial positions are typically the thermodynamically favored isomers. ${ }^{4 d, 17}$ This arrangement was confirmed by NMR analysis and DFT calculations with a diastereomeric ratio of 90:10 in favor of the trans-isomer for $\mathbf{4 b}$ in the isolated product (see SI for the assignment of the stereochemistry).

Based on these optimized reaction conditions, several secondary alcohols with different functional groups and varying steric demands were reacted with 3-methylpentane-1,5-diol $\mathbf{3 b}$ in order to explore the scope of the reaction (see Chart 1). Replacing the phenyl ring with a naphthyl ring afforded the corresponding product $4 \mathrm{c}$ in $86 \%$ GC yield and $83 \%$ isolated yield with a 87:13 diastereomeric ratio. Methyl substitution of 1-phenylethanol in the para- or ortho-position also gave the cyclohexyl product in high yield with the preferential formation of the trans-diastereomer (Chart 1, 4d and 4e). Reaction with the para-methoxy substituted secondary alcohol afforded the desired product in high yield (78\% GC yield), while the orthomethoxy substituted derivative showed somewhat lower selectivity ( $52 \%$ GC yield, see Chart $1, \mathbf{4 f}$ and $\mathbf{4 g}$ ). The reaction with 1-(4-chlorophenyl)ethanol showed excellent conversion but resulted in the formation of a mixture of products under standard conditions. However, when the reaction time was decreased to $14 \mathrm{~h}$, the desired cyclohexyl product $4 \mathrm{~h}$ was obtained in up to $70 \%$ GC yield and $61 \%$ isolated yield with very high selectivity to trans-diastereomer (Chart 1 , entry $4 \mathrm{~h}$ ). Bromo substitution in the para-position of 1-phenylethanol showed a $40 \%$ yield to the corresponding cyclohexyl product $4 \mathbf{i}$ after $14 \mathrm{~h}$ reaction time. However, debromination also occurred accounting for another 33\% of cyclization product. Interestingly, heterocyclic-secondary alcohol 1-(furan-2-yl)ethan-1-ol also revealed 61\% isolated yield to the cyclohexyl product $\mathbf{4 j}$.

Aliphatic alcohols comprising less acidic $\beta-\mathrm{CH}$ proton than the benzylic substrates also reacted smoothly. 1-Cyclohexylethanol yielded the desired cyclohexyl product $4 \mathbf{k}$ in good yield. However, in this case, low diastereomeric selectivity was observed (Chart 1, entry 4k). Small aliphatic secondary alcohols such as 3-methylbutan-2-ol and isopropyl 
Chart 1. Manganese-Catalyzed Synthesis of Substituted Cyclohexanes from a Variety of Secondary Alcohols and Diols $^{a, b}$

$$
=\underset{2}{\text { aryl, alkyl }} \underset{\mathrm{R}_{1}, \mathrm{R}_{2}=\mathrm{H} \text {, alkyl, aryl }}{\mathrm{R}_{3}}
$$

Conversion (\%) / GC Yield (Isolated Yield)<smiles>OC(c1ccccc1)C1CCCCC1</smiles><smiles>CC1CCC(C(O)c2ccccc2)CC1</smiles>
$90: 10 \mathrm{dr}$<smiles>Cc1ccccc1C(O)C1CCC(C)CC1</smiles>
$92.8 \mathrm{dr}$<smiles>COc1ccccc1C(O)C1CCC(C)CC1</smiles>
$>99 / 52(44)$ $88: 12$ d.r.

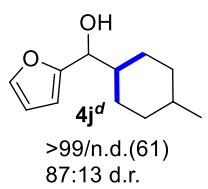<smiles>CC1CCC2C(C1)CC1CCC(C)CC1C2O</smiles>
$>99 /$ n.d. $(51)$ 78:22:0 d.r.
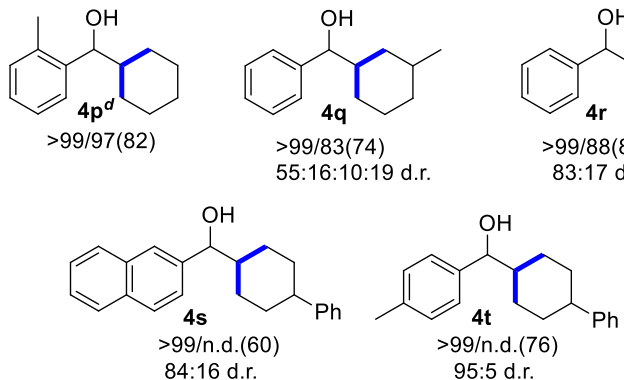

${ }^{a}$ Reaction conditions: secondary alcohol $2(0.5 \mathrm{mmol})$, diol 3 (2 $\mathrm{mmol}$ ), Mn-complex 1 (5 mg, $2 \mathrm{~mol} \%), \mathrm{KO}^{t} \mathrm{Bu}(224 \mathrm{mg}, 2 \mathrm{mmol}$ ), and toluene $(2 \mathrm{~mL})$ were heated in a closed vessel. ${ }^{b}$ Conversion and yield were calculated using GC analysis. Yields in parentheses correspond to isolated yields after purification via column chromatography. ${ }^{c}$ Reaction time: 14 h. ${ }^{d} 1.5 \mathrm{mmol}$ of diol was used. ${ }^{e}$ Three mmol of diol and $4 \mathrm{mmol}$ of $\mathrm{KO}^{t} \mathrm{Bu}$ were used. n.d.: not determined.

alcohol also confirmed good reactivity and high selectivity to the trans-diastereomer (Chart 1, entry 4l, 4m). By using isopropyl alcohol as a substrate two cyclohexyl ring formations were made possible.

Next, a variety of alkyl and aryl substituted diols were coupled with a range of secondary alcohols using the same optimized reaction conditions. The corresponding cyclohexane products were obtained in very good yields and with fair to high diastereoselectivity, further confirming the general efficiency and versatility of this synthetic methodology (Chart 1).

Assuming that dehydrogenation of the secondary alcohol is a crucial step in the reaction sequence (vide infra), ketones 5a and $\mathbf{5 b}$ were also tested in the reaction (see Chart 2).

Chart 2. Manganese-Catalyzed Selective Preparation of Substituted Cycloalkanes from Ketones and Diols ${ }^{a, b}$

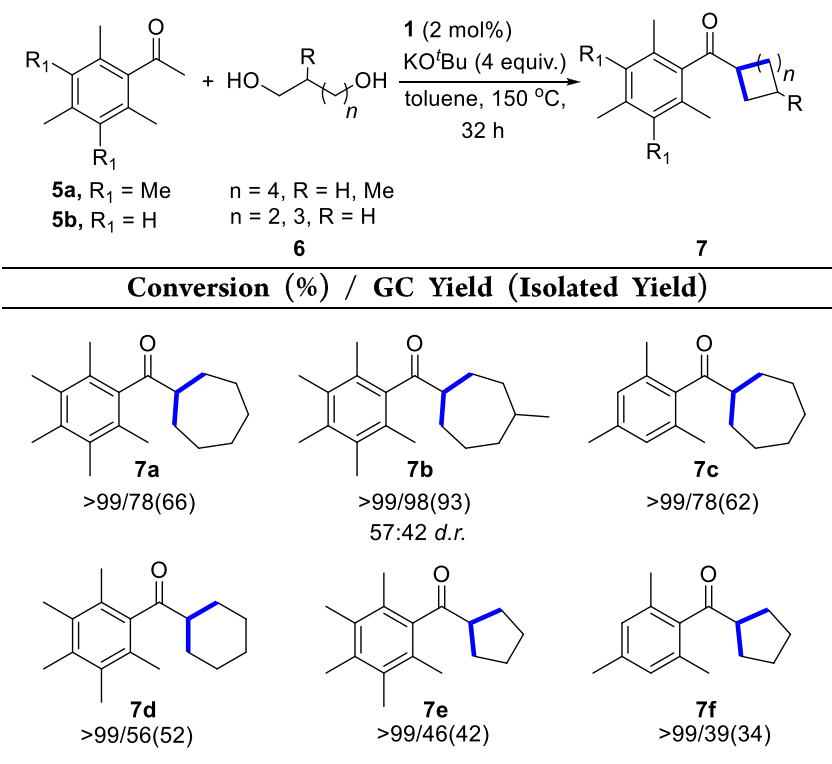

${ }^{a}$ Reaction conditions: 1-(methylpolysubstituted-phenyl)-ethanone 5 (0.5 mmol), diol 6 ( $2 \mathrm{mmol})$, Mn-complex 1 ( $5 \mathrm{mg}, 2 \mathrm{~mol} \%), \mathrm{KO}^{t} \mathrm{Bu}$ $(224 \mathrm{mg}, 2 \mathrm{mmol})$, and toluene $(2 \mathrm{~mL})$ were heated in a closed vessel. ${ }^{b}$ Conversion and yield were calculated using GC analysis. Yields in parentheses correspond to isolated yields after purification via column chromatography.

Interestingly, their use yielded selectively the ketone products; the corresponding alcohol derivatives were not observed. While the steric hindrance in these substrates reduced the reactivity to form the six-membered cycle somewhat giving only $52 \%$ yield of product $7 \mathrm{~d}$, it proved beneficial for synthesis of five- and seven-membered cycloalkanes. The reaction of 1,6hexanediol with pentamethyl acetophenone 5a led to formation of the desired seven-membered ring species $7 \mathbf{a}$ with very good yield and high selectivity (78\% GC yield and $66 \%$ isolated yield). Reaction of methyl substituted 1,6hexanediol with 5 a also provided to the cycloheptane product $7 \mathbf{b}$ with excellent $98 \%$ yield. The methyl substitution of the ketone derivative was reduced from 5a to 1-mesitylethanone $5 \mathbf{b}$ without altering the efficiency of the reaction (see formation of $7 \mathrm{c}$ in good yield: $78 \%$ by GC, $62 \%$ as isolated yield). The reaction of 5 a with 1,4-butanediol gave the fivemembered ring product in $46 \%$ yield (Chart 2 ). In a similar manner, the reaction of $\mathbf{5 b}$ with 1,4-butanediol afforded the expected cyclopentane derivative with a $39 \%$ yield. The reaction of secondary alcohols with 1,4-butanediol and 1,6hexanediol to prepare five- and seven-membered rings revealed only a mixture of products. Similarly, attempts to prepare fourmembered rings from 1,3-propanediol either with the ketone 
or secondary alcohol did not yet yield synthetically useful yields.

The overall reaction of the new synthetic protocol requires a complex sequence of several individual transformations to assemble the cycloalkane rings. Several control experiments support the assumption that it follows a Guerbet-type de/ rehydrogenation-condensation mechanism. Reactions without either complex 1 or $\mathrm{KO}^{t} \mathrm{Bu}$ did not show any product formation which confirmed that the reaction requires both the manganese complex and the base to achieve the desired reaction sequence. While the reaction with 1-phenyethanol 2a resulted in alcohol $\mathbf{4 a}$ as product (Table 1, entry 11), the coupling of sterically more hindered 1-mesitylethanol $\mathbf{8}$ with 1,5-pentanediol 3a resulted in the selective formation of ketone 9 as product with $37 \%$ isolated yield (Scheme 2). This can be

Scheme 2. Control Experiments To Probe Hydrogen Borrowing as Metal-Catalyzed Step of the Overall Reaction Sequence<smiles>[CH2-]C(O)c1c(C)cc(C)cc1C</smiles>

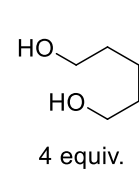

3a<smiles>CC(=O)c1ccccc1</smiles>

10<smiles>O=C(O)O</smiles>
$\underset{\text { toluene, } 150^{\circ} \mathrm{C} \text {, }}{\stackrel{\mathrm{KO}^{t} \mathrm{Bu}(4 \text { equiv) }}{\longrightarrow}}$ 3b

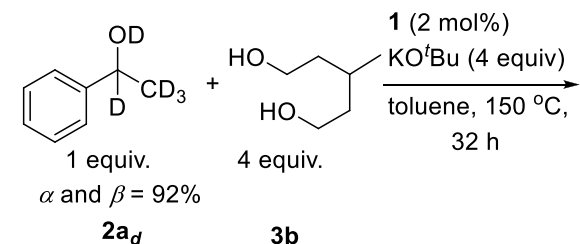
$2 \mathbf{a}_{d}$ $3 b$
$1(2 \mathrm{~mol} \%)$ $32 \mathrm{~h}$

$1(2 \mathrm{~mol} \%)$

$\mathrm{KO}^{t} \mathrm{Bu}$ (4 equiv) $32 \mathrm{~h}$

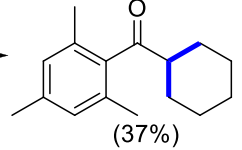

$(37 \%)$

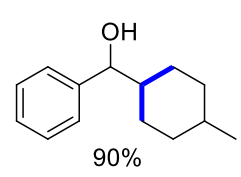

$86: 14$ d.r.

$4 b$

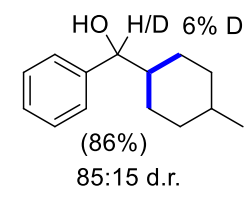

$\mathbf{4} \mathbf{b}_{d}$ rationalized assuming that ketone $\mathbf{5 b}$ is formed from $\mathbf{8}$ as intermediate, but the $\mathrm{C}=\mathrm{O}$ group in the product cannot be rehydrogenated due to steric hindrance. To verify the hypothesis, the reaction of acetophenone $\mathbf{1 0}$ with $\mathbf{3 b}$ was performed. Indeed, the alcohol product $\mathbf{4 b}$ was obtained in $90 \%$ GC yield with a $86: 14$ diastereomeric ratio (Scheme 2), very similar to that obtained when starting from the alcohol $2 \mathrm{a}$ (Table 1, entry 12). Reacting deuterium-labeled 1-phenylethanol ( 1 equiv) $2 a_{d}$ with $3 b$ ( 4 equiv) gave product $4 b_{d}$ with only very low deuterium content, confirming large degrees of $\mathrm{H} / \mathrm{D}$ scrambling in agreement with a hydrogen borrowing mechanism (Scheme 2).

On the basis of these experimental data and literature precedence, ${ }^{18}$ a plausible reaction sequence illustrating the role of the Mn-catalyst and the base is proposed in Scheme 3 (a more detailed representation is given in the SI). In the presence of $\mathrm{KO}^{t} \mathrm{Bu}$, complex $\mathbf{1}$ is converted to the amido complex $\mathbf{I})^{18 \mathrm{~b}, \mathrm{c}}$ a type of $\mathrm{Mn}(\mathrm{I})$ complexes that is well-known for its activity in hydrogen-transfer reactions. ${ }^{18 a, b}$ The formation was also verified by ${ }^{31} \mathrm{P}$ NMR in the present case (see the SI). Dehydrogenation occurs via reaction of I with secondary alcohol $\mathbf{A}$ or diol $\mathbf{A}^{\prime}$ to $\mathbf{M n}$-alkoxy amino complexes II and II' followed by $\beta$-hydride elimination to give ketone $\mathbf{B}$ and aldehyde $\mathbf{B}^{\prime}$, respectively. In the presence of base, aldol-
Scheme 3. Proposed Reaction Sequence and the Role of the Mn-Catalyst for the Synthesis of Substituted Cycloalkanes from Diols and Secondary Alcohols

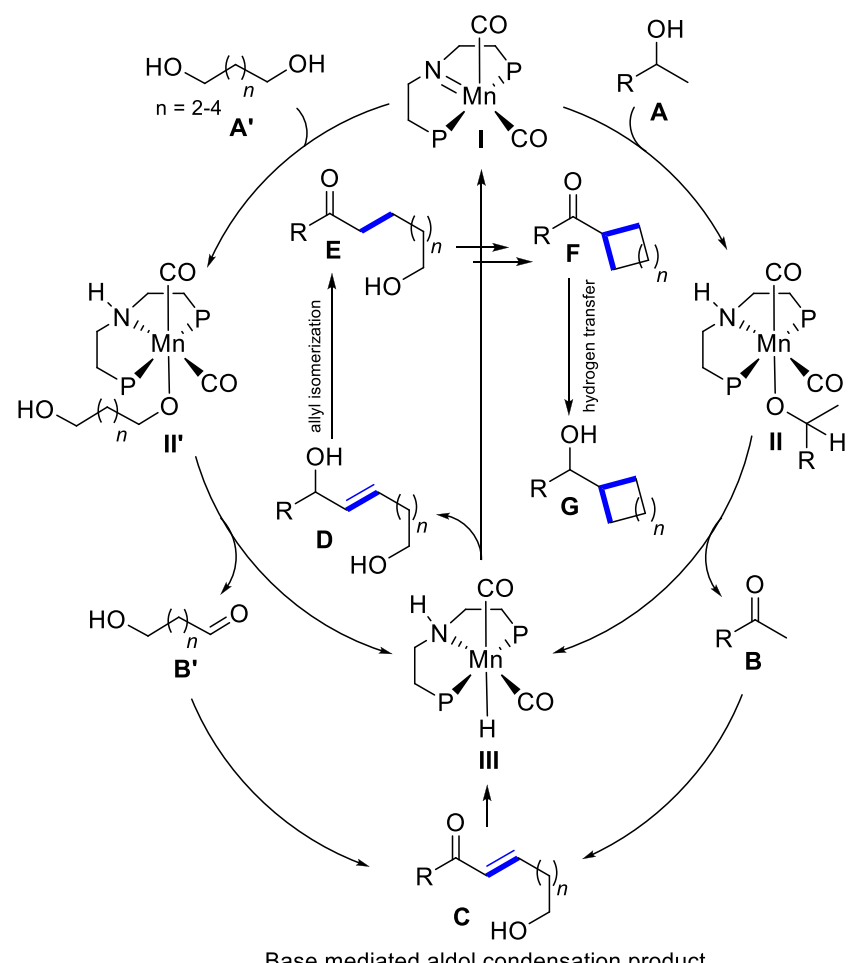

Base mediated aldol condensation product

condensation takes place between $\mathbf{B}$ and $\mathbf{B}^{\prime}$ to form the corresponding enone $\mathbf{C}$. The manganese hydride intermediate III that originates from $\beta$-hydride elimination ${ }^{14 \mathrm{~b}, 18 \mathrm{~b}}$ rehydrogenates the $\mathrm{C}=\mathrm{O}$ unit of $\mathrm{C}$ to the corresponding enol product $\mathrm{D}$, thereby regenerating the active Mn-species $\mathrm{I}$. Basecatalyzed allyl isomerization of enol $\mathbf{D}$ leads to the corresponding hydroxy ketone $\mathbf{E},{ }^{19}$ from which the analogous sequence starts again whereby intramolecular aldol-condensation fabricates the cyclic structure. Depending on the steric hindrance of the ketone moiety, the reaction may stop at product $\mathbf{F}$ or involve another rehydrogenation step to result in alcohol $\mathbf{G}$ as the final product.

In conclusion, we have developed an efficient and versatile synthetic strategy to prepare substituted cycloalkanes via catalytic coupling of diols and secondary alcohols/ketones using an earth-abundant and air-stable manganese pincer complex. Various aromatic and aliphatic secondary alcohols were coupled with several substituted 1,5-pentanediols to generate substituted cyclohexane rings with very good to high yield and moderate to high diastereoselectivity. Notably, the same methodology allows the catalytic synthesis of cycloheptane and cyclopentane rings by variation of the carbon chain in the diol component, reaching high to excellent yields for challenging cycloheptane derivatives. The reaction principle is atom economic producing only water as stoichiometric byproduct. Presently, however, an excess diol is required due to formation of intramolecular side products such as lactones. Further optimization to suppress this path would be facilitated by a more detailed understanding of the complex reaction network and the factors controlling the rates of the individual steps. While the Mn-catalyst affects primarily the de- and rehydrogenations steps, the base mediates probably the $\mathrm{C}-\mathrm{C}$ bond formation and isomerization. Given the significant 
importance of substituted-cycloalkane structures, further developments of this novel catalytic synthesis using a combination of molecular design and reaction engineering appear very promising.

\section{ASSOCIATED CONTENT}

\section{S Supporting Information}

The Supporting Information is available free of charge on the ACS Publications website at DOI: 10.1021/jacs.9b08832.

Detailed description of synthetic protocol, full analytical data, and additional information regarding mechanistic proposal (PDF)

\section{AUTHOR INFORMATION}

\section{Corresponding Author}

*walter.leitner@cec.mpg.de

\section{ORCID}

Clément Camp: 0000-0001-8528-0731

Walter Leitner: 0000-0001-6100-9656

\section{Notes}

The authors declare no competing financial interest.

\section{ACKNOWLEDGMENTS}

The studies were performed as part of our activities in the framework of the "Fuel Science Center" funded by the Deutsche Forschungsgemeinschaft (DFG, German Research Foundation) under Germany's Excellence Strategy - Exzellenzcluster 2186, The Fuel Science Center“ ID: 390919832. A.K. thanks the Erasmus Mundus Action 1 Programme (FPA2013- 0037) "SINCHEM" for a stipend. We are thankful to David A. Kuß for performing the DFT calculation. We gratefully acknowledge the CPE Lyon, its sustainable development chair, CNRS, and University of Lyon 1 for the support, the experimental infrastructure, and the internship of L.-L.G.

\section{REFERENCES}

(1) (a) Xia, G.; Han, X.; Lu, X. Pd(II)-Catalyzed One-Step Construction of Cycloalkane-Fused Indoles and Its Application in Formal Synthesis of ( \pm )-Aspidospermidine. Org. Lett. 2014, 16 (7), 2058-2061. (b) Banerjee, A.; Sarkar, S.; Patel, B. K. C-H functionalisation of cycloalkanes. Org. Biomol. Chem. 2017, 15 (3), 505-530. (c) Bravo, L.; Mico, J. A.; Berrocoso, E. Discovery and development of tramadol for the treatment of pain. Expert Opin. Expert Opin. Drug Discovery 2017, 12 (12), 1281-1291. (d) Goudedranche, S.; Raimondi, W.; Bugaut, X.; Constantieux, T.; Bonne, D.; Rodriguez, J. Enantioselective Organocatalyzed Domino Synthesis of Six-Membered Carbocycles. Synthesis 2013, 45 (14), 1909-1930. (e) Ansell, M. F. Supplements to the 2nd Edition of Rodd's Chemistry of Carbon Compounds. In A Modern Comprehensive Treatise; 2008; Vol. 2, DOI: 10.1016/B978-0-444-53346-3.X5001-X. (f) Holton, R. A.; Somoza, C.; Kim, H. B.; Liang, F.; Biediger, R. J.; Boatman, P. D.; Shindo, M.; Smith, C. C.; Kim, S. First total synthesis of taxol. 1. Functionalization of the B ring. J. Am. Chem. Soc. 1994, 116 (4), 1597-1598. (g) Dabrowski, J. A.; Moebius, D. C.; Wommack, A. J.; Kornahrens, A. F.; Kingsbury, J. S. Catalytic and Regioselective Ring Expansion of Arylcyclobutanones with Trimethylsilyldiazomethane. Ligand-Dependent Entry to $\beta$-Ketosilane or Enolsilane Adducts. Org. Lett. 2010, 12 (16), 3598-3601.

(2) (a) Booker-Milburn, K. I.; Sharpe, A. Saturated and partially unsaturated carbocycles. J. Chem. Soc., Perkin Trans. 1 1998, 1 (5), 983-1006. (b) Smith, M. B.; March, J. March's Advanced Organic Chemistry: Reactions, Mechanisms, and Structure, 6th ed.; 2006.

(3) (a) Ding, X.; Wang, H.; Wang, J.; Wang, S.; Lin, D.; Lv, L.; Zhou, Y.; Luo, X.; Jiang, H.; Aceña, J. L.; Soloshonok, V. A.; Liu, H.
Synthesis of polysubstituted $\beta$-amino cyclohexane carboxylic acids via Diels-Alder reaction using $\mathrm{Ni}(\mathrm{II})$-complex stabilized $\beta$-alanine derived dienes. Amino Acids 2013, 44 (2), 791-796. (b) Danishefsky, S.; Kitahara, T. Useful diene for the Diels-Alder reaction. J. Am. Chem. Soc. 1974, 96 (25), 7807-7808. (c) Corey, E. J. Catalytic Enantioselective Diels-Alder Reactions: Methods, Mechanistic Fundamentals, Pathways, and Applications. Angew. Chem., Int. Ed. 2002, 41 (10), 1650-1667.

(4) (a) Stalzer, M. M.; Nicholas, C. P.; Bhattacharyya, A.; Motta, A.; Delferro, M.; Marks, T. J. Single-Face/All-cis Arene Hydrogenation by a Supported Single-Site d0 Organozirconium Catalyst. Angew. Chem., Int. Ed. 2016, 55 (17), 5263-5267. (b) Peters, B. K.; Liu, J.; Margarita, C.; Rabten, W.; Kerdphon, S.; Orebom, A.; Morsch, T.; Andersson, P. G. Enantio- and Regioselective Ir-Catalyzed Hydrogenation of Di- and Trisubstituted Cycloalkenes. J. Am. Chem. Soc. 2016, 138 (36), 11930-11935. (c) Wang, Y.; Cui, X.; Deng, Y.; Shi, F. Catalytic hydrogenation of aromatic rings catalyzed by $\mathrm{Pd} / \mathrm{NiO}$. RSC Adv. 2014, 4 (6), 2729-2732. (d) Wiesenfeldt, M. P.; Nairoukh, Z.; Dalton, T.; Glorius, F. Selective Arene Hydrogenation for Direct Access to Saturated Carbo- and Heterocycles. Angew. Chem., Int. Ed. 2019, 58 (31), 10460-10476. (e) Wang, D.-S.; Chen, Q.-A.; Lu, S.M.; Zhou, Y.-G. Asymmetric Hydrogenation of Heteroarenes and Arenes. Chem. Rev. 2012, 112 (4), 2557-2590.

(5) (a) Wurtz, A. Ueber eine neue Klasse organischer Radicale. Justus Liebigs Annalen der Chemie 1855, 96 (3), 364-375. (b) Lampman, G. M.; Aumiller, J. C. Bicyclo[1.1.0]Butane. Org. Synth. 1971, $51,55$.

(6) (a) Schneider, T. F.; Kaschel, J.; Werz, D. B. A New Golden Age for Donor-Acceptor Cyclopropanes. Angew. Chem., Int. Ed. 2014, 53 (22), 5504-5523. (b) Ma, W.; Fang, J.; Ren, J.; Wang, Z. Lewis Acid Catalyzed Formal Intramolecular [3 +3$]$ Cross-Cycloaddition of Cyclopropane 1,1-Diesters for Construction of Benzobicyclo[2.2.2]octane Skeletons. Org. Lett. 2015, 17 (17), 4180-4183.

(7) (a) Schick, H.; Roatsch, B.; Schwarz, H.; Hauser, A.; Schwarz, S. Syntheses and Reactions of 2,2-Disubstituted Cyclopentane-1,3diones, 6. Conversion of 2-Methylcyclopentane-1,3-dione into 5Methylcycloheptane-1,4-dione via 3-(1-Methyl-2,5-dioxocyclopentyl)propanal. Liebigs Ann. Chem. 1992, 1992 (5), 419-422. (b) Jung, M. E. 1.1 - Stabilized Nucleophiles with Electron Deficient Alkenes and Alkynes. In Comprehensive Organic Synthesis; Trost, B. M., Fleming, I., Eds.; Pergamon: Oxford, 1991; pp 1-67.

(8) (a) Oppolzer, W. The intramolecular $[2+2]$ photoaddition/ cyclobutane-fragmentation sequence in organic synthesis. Acc. Chem. Res. 1982, 15 (5), 135-141. (b) De Mayo, P. Photochemical syntheses. 37. Enone photoannelation. Acc. Chem. Res. 1971, 4 (2), 41-47.

(9) (a) Haraguchi, R.; Takada, Y.; Matsubara, S. Preparation of cycloheptane ring by nucleophilic cyclopropanation of 1,2-diketones with bis(iodozincio)methane. Org. Biomol. Chem. 2015, 13 (1), 241247. (b) Takada, Y.; Nomura, K.; Matsubara, S. Preparation of a Cycloheptane Ring from a 1,2-Diketone with High Stereoselectivity. Org. Lett. 2010, 12 (22), 5204-5205. (c) Ragan, J. A.; Makowski, T. W.; am Ende, D. J.; Clifford, P. J.; Young, G. R.; Conrad, A. K.; Eisenbeis, S. A. A Practical Synthesis of Cycloheptane-1,3-dione. Org. Process Res. Dev. 1998, 2 (6), 379-381.

(10) (a) Renaud, J.; Ouellet, S. G. Novel Synthesis of Cyclic Alkenylboronates via Ring-Closing Metathesis. J. Am. Chem. Soc. 1998, 120 (31), 7995-7996. (b) Jana, A.; Misztal, K.; Żak, A.; Grela, K. Synthesis of Selectively Substituted or Deuterated Indenes via Sequential Pd and Ru Catalysis. J. Org. Chem. 2017, 82 (8), 42264234. (c) Ogba, O. M.; Warner, N. C.; O'Leary, D. J.; Grubbs, R. H. Recent advances in ruthenium-based olefin metathesis. Chem. Soc. Rev. 2018, 47 (12), 4510-4544. (d) Maier, M. E. Synthesis of Medium-Sized Rings by the Ring-Closing Metathesis Reaction. Angew. Chem., Int. Ed. 2000, 39 (12), 2073-2077.

(11) (a) Michelet, V.; Toullec, P. Y.; Genêt, J.-P. Cycloisomerization of 1,n-Enynes: Challenging Metal-Catalyzed Rearrangements and Mechanistic Insights. Angew. Chem., Int. Ed. 2008, 47 (23), 42684315. (b) Böing, C.; Franciò, G.; Leitner, W. Nickel catalysed 
asymmetric cycloisomerisation of diethyl diallylmalonate. Chem. Commun. 2005, 11, 1456-1458. (c) Stevenson, S. M.; Newcomb, E. T.; Ferreira, E. M. C-C bond migration in the cycloisomerization of 1,6-enynes. Org. Chem. Front. 2016, 3 (10), 1228-1235. (d) Fürstner, A. Gold and platinum catalysis-a convenient tool for generating molecular complexity. Chem. Soc. Rev. 2009, 38 (11), 3208-3221. (e) Stathakis, C. I.; Gkizis, P. L.; Zografos, A. L. Metalcatalyzed cycloisomerization as a powerful tool in the synthesis of complex sesquiterpenoids. Nat. Prod. Rep. 2016, 33 (9), 1093-1117. (12) (a) Corma, A.; Navas, J.; Sabater, M. J. Advances in One-Pot Synthesis through Borrowing Hydrogen Catalysis. Chem. Rev. 2018, 118 (4), 1410-1459. (b) Reed-Berendt, B. G.; Polidano, K.; Morrill, L. C. Recent advances in homogeneous borrowing hydrogen catalysis using earth-abundant first row transition metals. Org. Biomol. Chem. 2019, 17 (7), 1595-1607. (c) Irrgang, T.; Kempe, R. 3d-Metal Catalyzed N- and C-Alkylation Reactions via Borrowing Hydrogen or Hydrogen Autotransfer. Chem. Rev. 2019, 119 (4), 2524-2549.

(13) (a) Hamid, M. H. S. A.; Slatford, P. A.; Williams, J. M. J. Borrowing Hydrogen in the Activation of Alcohols. Adv. Synth. Catal. 2007, 349 (10), 1555-1575. (b) Nixon, T. D.; Whittlesey, M. K.; Williams, J. M. J. Transition metal catalysed reactions of alcohols using borrowing hydrogen methodology. Dalton Trans 2009, No. 5, 753-762. (c) Liu, T.; Wang, L.; Wu, K.; Yu, Z. Manganese-Catalyzed $\beta$-Alkylation of Secondary Alcohols with Primary Alcohols under Phosphine-Free Conditions. ACS Catal. 2018, 8 (8), 7201-7207. (d) Elangovan, S.; Sortais, J.-B.; Beller, M.; Darcel, C. Iron-Catalyzed $\alpha$-Alkylation of Ketones with Alcohols. Angew. Chem., Int. Ed. 2015, 54 (48), 14483-14486. (e) Yang, J.; Liu, X.; Meng, D.-L.; Chen, H.Y.; Zong, Z.-H.; Feng, T.-T.; Sun, K. Efficient Iron-Catalyzed Direct $\beta$-Alkylation of Secondary Alcohols with Primary Alcohols. Adv. Synth. Catal. 2012, 354 (2-3), 328-334. (f) Fujita, K.-i.; Asai, C.; Yamaguchi, T.; Hanasaka, F.; Yamaguchi, R. Direct $\beta$-Alkylation of Secondary Alcohols with Primary Alcohols Catalyzed by a Cp*Ir Complex. Org. Lett. 2005, 7 (18), 4017-4019. (g) Chakraborty, S.; Daw, P.; Ben David, Y.; Milstein, D. Manganese-Catalyzed $\alpha$ Alkylation of Ketones, Esters, and Amides Using Alcohols. ACS Catal. 2018, 8 (11), 10300-10305. (h) El-Sepelgy, O.; Matador, E.; Brzozowska, A.; Rueping, M. C-Alkylation of Secondary Alcohols by Primary Alcohols through Manganese-Catalyzed Double Hydrogen Autotransfer. ChemSusChem 2019, 12 (13), 3099-3102. (i) Barman, M. K.; Jana, A.; Maji, B. Phosphine-Free NNN-Manganese Complex Catalyzed $\alpha$-Alkylation of Ketones with Primary Alcohols and Friedländer Quinoline Synthesis. Adv. Synth. Catal. 2018, 360 (17), 3233-3238. (j) Bruneau-Voisine, A.; Pallova, L.; Bastin, S.; César, V.; Sortais, J.-B. Manganese catalyzed $\alpha$-methylation of ketones with methanol as a C1 source. Chem. Commun. 2019, 55 (3), 314-317. (k) Gawali, S. S.; Pandia, B. K.; Pal, S.; Gunanathan, C. Manganese(I)-Catalyzed Cross-Coupling of Ketones and Secondary Alcohols with Primary Alcohols. ACS Omega 2019, 4 (6), 1074110754. (1) Gawali, S. S.; Pandia, B. K.; Gunanathan, C. Manganese(I)Catalyzed $\alpha$-Alkenylation of Ketones Using Primary Alcohols. Org. Lett. 2019, 21 (10), 3842-3847.

(14) (a) Kaithal, A.; Schmitz, M.; Hölscher, M.; Leitner, W. Ruthenium(II)-Catalyzed $\beta$-Methylation of Alcohols using Methanol as C1 Source. ChemCatChem 2019, DOI: 10.1002/cctc.201900788. (b) Hoelscher, M.; Kaithal, A.; van Bonn, P.; Leitner, W. Manganese(I)-Catalyzed $\beta$-Methylation of Alcohols using Methanol as C1 Source. Angew. Chem., Int. Ed. 2019, DOI: 10.1002/ anie.201909035.

(15) Akhtar, W. M.; Armstrong, R. J.; Frost, J. R.; Stevenson, N. G.; Donohoe, T. J. Stereoselective Synthesis of Cyclohexanes via an Iridium Catalyzed $(5+1)$ Annulation Strategy. J. Am. Chem. Soc. 2018, 140 (38), 11916-11920.

(16) (a) Garbe, M.; Junge, K.; Beller, M. Homogeneous Catalysis by Manganese-Based Pincer Complexes. Eur. J. Org. Chem. 2017, 2017 (30), 4344-4362. (b) Zhang, C.; Zhao, J.-P.; Hu, B.; Shi, J.; Chen, D. Ruthenium-Catalyzed $\beta$-Alkylation of Secondary Alcohols and $\alpha$ Alkylation of Ketones via Borrowing Hydrogen: Dramatic Influence of the Pendant N-Heterocycle. Organometallics 2019, 38 (3), 654-664.
(17) (a) Härtner, J.; Reinscheid, U. M. Conformational analysis of menthol diastereomers by NMR and DFT computation. J. Mol. Struct. 2008, 872 (2-3), 145-149. (b) Dragojlovic, V. Conformational analysis of cycloalkanes. ChemTexts 2015, 1 (3), 14.

(18) (a) Fu, S.; Shao, Z.; Wang, Y.; Liu, Q. Manganese-Catalyzed Upgrading of Ethanol into 1-Butanol. J. Am. Chem. Soc. 2017, 139 (34), 11941-11948. (b) Kaithal, A.; Hölscher, M.; Leitner, W. Catalytic Hydrogenation of Cyclic Carbonates using Manganese Complexes. Angew. Chem., Int. Ed. 2018, 57 (41), 13449-13453. (c) Elangovan, S.; Garbe, M.; Jiao, H.; Spannenberg, A.; Junge, K.; Beller, M. Hydrogenation of Esters to Alcohols Catalyzed by Defined Manganese Pincer Complexes. Angew. Chem., Int. Ed. 2016, 55 (49), 15364-15368. (d) Martínez-Ferraté, O.; Werlé, C.; Franciò, G.; Leitner, W. Aminotriazole Mn(I) Complexes as Effective Catalysts for Transfer Hydrogenation of Ketones. ChemCatChem 2018, 10 (20), 4514-4518.

(19) Suchand, B.; Satyanarayana, G. KOtBu-Mediated Domino Isomerization and Functionalization of Aromatic Allylic Alcohols. Eur. J. Org. Chem. 2017, 2017 (26), 3886-3895. 